\title{
From biophysical to social-ecological trade-offs: integrating biodiversity conservation and agricultural production in the Argentine Dry Chaco
}

\author{
Matias E. Mastrangelo $^{1}$ and Pedro Laterra ${ }^{1}$
}

\begin{abstract}
Agricultural intensification in rural areas of developing countries compromises the provision of ecosystem services. Social conflict arises among landholders with different preferences for ecosystem services and land-use practices in agricultural frontiers of the Argentine Dry Chaco. We explored policy and management options by assessing the actual and potential outcomes of alternative land-use systems and scenarios. We first constructed the efficiency frontier for avian habitat and agricultural productivity to analyze the combinations of ecosystem services that can be achieved under different land-use intensities. A nonlinear, concave efficiency frontier indicated opportunities to achieve large gains for production with small losses for conservation, for instance, by transitioning from low- to intermediate-intensity systems. Second, we projected production and conservation outcomes, which can be achieved through the implementation of five alternative policy options. The land sharing with conservation scenario, $70 \%$ of the landscape covered by intermediate-intensity systems and $30 \%$ by undisturbed forests, yielded the higher combination of avian habitat and agricultural productivity. Third, we constructed indifference curves of three landholder groups, i.e., preproductivist, multifunctional, and productivist, by assessing their intentions (proxies for preferences) to conserve and convert remnant forests in their landholdings. Multifunctional landholders showed balanced preferences for conserving and converting forests in their landholdings, and maintaining intermediate-intensity systems. A general willingness to conserve forests coexisted in preproductivist landholders with the intention to clear some portions of the landholding and intensify landuse, indicating the potential of an endogenously motivated transition toward a multifunctional regime. Such transition may increase their productivity by $35-65 \%$ without compromising avian habitat. Productivist landholders showed a strong inclination toward converting forests for pasture cultivation, despite the observation that they can increase their conservation outcomes by $30-50 \%$ without significantly reducing productivity by transitioning toward a multifunctional regime. Promoting this transition will require exogenous incentives and regulations tailored to the behavior of this landholder group.
\end{abstract}

Key Words: Dry Chaco; ecosystem services; efficiency frontier; indifference curve; multifunctional systems; trade-offs

\section{INTRODUCTION}

Land-use intensification in rural areas of developing countries to increase the production of agricultural commodities compromises the provision of ecosystem services of relevance at local, regional, and global scales. Archetypal scenarios of rural tropics portray local landholders intensifying and expanding agricultural production, whereas global conservation organizations seek to conserve remnant native ecosystems. However, social and environmental characteristics can be very different from place to place, as can the influences from higher spatial scales, owing to historical and political factors. Land-use policies should thus be matched to social contexts and ecological scales if they are to yield efficient and equitable outcomes (Hein et al. 2006, Ostrom 2009). Knowing how environmental heterogeneity influences the biophysical production and trade-offs between ecosystem services is necessary to increase land-use efficiency (Grau et al. 2013). This knowledge, however, is not sufficient to promote both efficient and equitable land-use outcomes, unless it is complemented with an understanding of how differences in stakeholders' preferences for and access to ecosystem services influence the social distribution of benefits.

In the Argentine Dry Chaco, the combination of increasing rainfall, land privatization, technological advances for dryland agriculture, and the increasing influence of extraregional stakeholders stimulated an accelerated expansion of industrial agriculture and deforestation in the last two decades, i.e., annual rates of $1-1.5 \%$ for 2002-2009 (Vallejos et al. 2014). Dry Chaco agricultural frontiers are today the stage of strong social conflicts around the access to and utilization of ecosystem services among landholders with contrasting land-use systems, decision-making logics, and socioeconomic connectivity to higher spatial scales (Mastrangelo and Gavin 2012, Mastrangelo et al. 2014a). Different land-use policy options aimed at more equitable and efficient outcomes are being proposed from research, advocacy, and policy sectors, both governmental and nongovernmental (Grau et al. 2008, Seghezzo et al. 2011). Previous analyses found merits for both land sharing (Mastrangelo and Gavin 2012) and land sparing (Macchi et al. 2013) by assessing trade-offs at the local scale. We used empirical data to explicitly compare the conservation and production outcomes resulting from the simulation of five alternative land-use policy scenarios.

Exploring the utility and viability of land-use policy options in complex social-ecological contexts requires frameworks that integrate the biophysical focus with the analysis of stakeholders' preferences for ecosystem services (Mastrangelo et al. 2014b). An important first step for an integrative framework is to identify the combinations of ecosystem services that can be jointly produced within the biophysical limits of the system, i.e., the efficiency or production possibility frontier (Smith et al. 2012, Cavender-Bares et al. 2015). The efficiency frontier can then be combined with the identification of socially desirable outcomes, for example, by assessing combinations of ecosystem services for which stakeholders achieve the same level of well-being, i.e., indifference curves (Cavender-Bares et al. 2015). We combined the analysis of the efficiency frontier and of the indifference curves to explore management and policy options for balancing agricultural productivity and avian diversity at agricultural frontiers of the Argentine Dry Chaco.

${ }^{1}$ Consejo Nacional de Investigaciones Científicas y Técnicas (CONICET) - Unidad Integrada Balcarce: EEA Balcarce, Instituto Nacional de Tecnología Agropecuaria - Facultad de Ciencias Agrarias 
Table 1. Empirical data used to project conservation and production outcomes under alternative land-use policy scenarios.

\begin{tabular}{lcccc}
\hline \hline & Forests & $\begin{array}{c}\text { Low-intensity } \\
\text { system }\end{array}$ & $\begin{array}{c}\text { Intermediate-intensity } \\
\text { system }\end{array}$ & High-intensity system \\
\hline Cattle productivity $^{-1}$ (kg.harar ${ }^{-1}$, median) & 0 & 12 & 100 & 115 \\
Tree cover (\%, mean \pm SD) & $81 \pm 14.2$ & $56 \pm 22.5$ & $37 \pm 9.4$ & $6 \pm 5.4$ \\
Total number of bird species & 97 & 79 & 63 & 42 \\
Number of forest specialist species & 54 & 38 & 20 & 1 \\
Number of habitat generalist species & 43 & 41 & 43 & 41 \\
Species shared with forests (\%) & 100 & 89 & 66 & 31 \\
\hline
\end{tabular}

\section{METHODS}

\section{Study area}

The Argentine Dry Chaco spans $>600,000 \mathrm{~km}^{2}$ in south central South America and contains the largest remnant tract of Neotropical dry forests, one of the most threatened and understudied biomes globally (Eva et al. 2004, Hoekstra et al. 2005). It has a rainfall gradient that creates a western and a central subhumid area with an annual rainfall $=800-1100 \mathrm{~mm}$, which surrounds a semiarid area with an annual rainfall $<800 \mathrm{~mm}$. The region was originally inhabited by 25 indigenous groups of 6 language families. New social actors arrived at different times: a cultural group of Spanish descent, i.e., criollos, settled in the late $19^{\text {th }}$ century, hundreds of communities of European immigrants, i.e., colonos, arrived in the early $20^{\text {th }}$ century, and wealthy farmers acquired large tracts of public lands in the last two decades (Morello et al. 2005). The latter group drove the rapid expansion of soybean cultivation over the subhumid fringes of the region and of pasture cultivation toward its semiarid core, causing the displacement of Indigenous communities and criollo families with weak or no land-tenure security (Grau et al. 2008).

\section{Efficiency frontier}

We based the construction of the efficiency frontier on the empirical trade-off model of Mastrangelo and Gavin (2012). In this model, a trade-off curve shows the combination of avian diversity and cattle productivity achieved at 27 landholdings, which used the land at different intensities in the BermejoPilcomayo Interfluve, i.e., an agricultural frontier landscape in the Argentine Dry Chaco. We adopted a definition of land-use intensification as the process of increasing cattle yields per unit land per unit time. Because intensification in this context involves ecosystem simplification, land-use intensity was indicated by the degree to which the vertical structure of native forests was reduced for the production of beef cattle (Table 1). To construct the efficiency frontier, we identified the landholdings along the tradeoff curve that realized the maximum combination of: (1) avian diversity found in the agricultural matrix relative to that found in the nearest fragment of native forest, and (2) beef cattle productivity, i.e., live cattle weight produced per hectare per annum) achieved in the landholding relative the agro-ecological potential, that is, the maximum achievable yields in that location given annual rainfall and land-use intensity (based on Berti 2009). Avian diversity contributes to several ecosystem services because birds are good estimators of the conservation value of tropical land-use systems (Schulze et al. 2004) and provide direct benefits to people (Whelan et al. 2008). We assumed that landholdings achieving the highest combinations of these ecosystem services for a given land-use intensity class, i.e., low, intermediate, and high, are those that make the most efficient use of the land. This way of depicting the efficiency frontier thereby reflects realworld constraints for diverse land-use systems, rather than theoretical limits.

\section{Land-use scenarios and outcomes}

Empirical data on cattle yields and avian diversity, overall and of habitat preference groups, (Table 1) at the landholding level was taken from Mastrangelo and Gavin (2012) to project landuse scenarios representing alternative policy options at the landscape level. We assumed that only local management factors influenced avian diversity in the agricultural matrix, because these were shown to have significantly higher influence than landscape-level factors (Mastrangelo and Gavin 2014). We projected five land-use scenarios, each consisting of a particular land-use composition of an arbitrarily defined spatial unit of 10,000 hectares (Table 2). In a Dry Chaco landscape of this size, there is low environmental heterogeneity, and outcomes are mostly determined by landholders' decisions under land-use policy constraints. The land-use scenarios were: (1) industrial agriculture: the landscape is dominated by land-use systems in which cattle graze on exotic pastures on lands cleared of native forests, i.e., high-intensity systems; (2) land-sparing: 70\% of the landscape is covered by high-intensity systems and $30 \%$ is covered by undisturbed native forests; (3) land-sharing: the landscape is dominated by silvopastoral systems in which cattle graze on exotic pastures growing under the shade of native trees, i.e., intermediate-intensity systems; (4) land-sharing with conservation: $70 \%$ of the landscape is covered by intermediateintensity systems and $30 \%$ by forest fragments; and (5) traditional ranching: the landscape is dominated by traditional land-use systems called puestos, in which cattle graze on native forests and grasslands, i.e., low-intensity systems.

For each scenario, we calculated one production outcome and four conservation outcomes. We compared these five variables across the five scenarios using a nonparametric analysis of variance (Kruskall-Wallis) and post hoc (HSD) tests in Infostat (Di Rienzo et al. 2008). We expressed the production outcome of a policy option, e.g., land-sharing, as the percentage of yields achieved under the corresponding land-use scenario, e.g., $100 \%$ intermediate-intensity systems, relative to the yields achieved under the scenario with the highest yields, i.e., industrial agriculture scenario. The conservation outcomes show how each policy option differed in the habitat quality provided to species 
Table 2. Production and conservation outcomes achieved under alternative land-use policy scenarios.

\begin{tabular}{|c|c|c|c|c|c|c|c|c|c|}
\hline \multirow[t]{2}{*}{ Policy option } & \multicolumn{4}{|c|}{ Land-use composition of scenarios (\%) } & \multirow{2}{*}{$\begin{array}{c}\text { Production } \\
\text { outcome }(\%){ }^{\dagger} \\
\text { Beef cattle } \\
\text { productivity }\end{array}$} & \multicolumn{4}{|c|}{ Conservation outcomes $(\%)^{\dagger}$} \\
\hline & $\begin{array}{l}\text { Native } \\
\text { forests }\end{array}$ & $\begin{array}{l}\text { Low- } \\
\text { intensity } \\
\text { systems }\end{array}$ & $\begin{array}{l}\text { Intermediate- } \\
\text { intensity systems }\end{array}$ & $\begin{array}{l}\text { High- } \\
\text { intensity } \\
\text { systems }\end{array}$ & & $\begin{array}{c}\text { Forest } \\
\text { specialist } \\
\text { spp. on core } \\
\vdots \\
\end{array}$ & $\begin{array}{l}\text { Forest } \\
\text { specialist } \\
\text { spp. on } \\
\text { matrix }\end{array}$ & $\begin{array}{c}\text { Habitat } \\
\text { generalist } \\
\text { spp. on core }\end{array}$ & $\begin{array}{c}\text { Habitat } \\
\text { generalist spp. } \\
\text { on matrix }\end{array}$ \\
\hline $\begin{array}{l}\text { Industrial } \\
\text { agriculture }\end{array}$ & 0 & 0 & 0 & 100 & $100^{\mathrm{a}}$ & $0^{\mathrm{a}}$ & $0.6^{\mathrm{a}}$ & $0^{\mathrm{a}}$ & $29.5^{\mathrm{a}}$ \\
\hline Land sharing & 0 & 0 & 100 & 0 & $86.9^{\mathrm{b}}$ & $0^{\mathrm{a}}$ & $24.4^{\mathrm{b}}$ & $0^{\mathrm{a}}$ & $66^{\mathrm{b}}$ \\
\hline Land sparing & 30 & 0 & 0 & 70 & $70^{\mathrm{bc}}$ & $100^{\mathrm{b}}$ & $0.6^{\mathrm{a}}$ & $100^{\mathrm{b}}$ & $29.5^{\mathrm{a}}$ \\
\hline $\begin{array}{l}\text { Land sharing } \\
\text { and } \\
\text { conservation }\end{array}$ & 30 & 0 & 70 & 0 & $61^{\mathrm{c}}$ & $100^{\mathrm{b}}$ & $24.4^{\mathrm{b}}$ & $100^{\mathrm{b}}$ & $66^{\mathrm{b}}$ \\
\hline $\begin{array}{l}\text { Traditional } \\
\text { ranching }\end{array}$ & 0 & 100 & 0 & 0 & $10.4^{\mathrm{d}}$ & $62.6^{\mathrm{c}}$ & $0^{\mathrm{a}}$ & $84.8^{\mathrm{b}}$ & $0^{\mathrm{c}}$ \\
\hline
\end{tabular}

for which forest is optimal habitat, i.e., forest specialists, and to species that can use forest and nonforest habitats, i.e., habitat generalists, in lands slightly modified (core habitat) and strongly modified (matrix habitat) by grazing management. We calculated each conservation outcome as:

$\left(\mathrm{R}_{\mathrm{X}} / \mathrm{R}_{\mathrm{FX}}\right) * \mathrm{~S}_{\mathrm{X}-\mathrm{F}}$

where $\mathrm{R}_{\mathrm{X}}$ and $\mathrm{R}_{\mathrm{FX}}$ are the richness of bird species, forest specialists or habitat generalists, found in the landholding $\mathrm{X}$ or in the forest fragment nearest to landholding $X$ (respectively), and $S_{X-F}$ is the species similarity of birds between the land-use system of landholding X and forest fragments. In this way, the conservation outcome of a policy option highlights the retention of Chaco bird species on matrix habitats, by accounting for the percentage of bird species usually restricted to forest habitats that can be found in grazing lands. We assumed all forest specialist species to be present in the landscape if the extent of undisturbed native forests was above the habitat threshold of $30 \%$ native tree cover found in Mastrangelo and Gavin (2012).

\section{Indifference curves of landholder types}

We classified ranchers and farmers of the study area into landholder types and evaluated their preferences to build grouplevel indifference curves. For this, we used qualitative and quantitative psycho-social data from several primary sources. First, we built a typology of landholders to simplify and characterize the diversity of landholders present in the context of Chaco agricultural frontiers. We adopted the classification and characterization of agricultural regimes developed by Wilson (2007). This author proposed that a salient identity across a group of farmers, and the set of management practices associated with it, can be conceptualized as an agricultural regime. We identified salient identities and associated set of beliefs, perceptions, and practices based on the qualitative analysis (open coding) of the content of 60 semistructured interviews to landholders collected in 2010 and 2011. We used qualitative cluster analysis to classify landholder types based on their underlying agricultural regimes. We use the term agricultural regimes, e.g. productivist, to refer to the integrated human and natural dimensions of landholdings, whereas we use land-use system to refer to the biophysical characteristics of the landholding, which result from using the land at certain intensity, e.g., high-intensity system.

Second, we evaluated preferences of landholder types for combinations of forest conservation and agricultural productivity. We used a self-reported measure of landholders' intentions to conserve remnant forest fragments in their landholding as a proxy of their preference for conservation outcomes. Similarly, we used a self-reported measure of landholders' intentions to convert forest remnants to pasture or crop cultivation in their landholding as a proxy of their preference for agricultural productivity. The target of the intention was unspecific, e.g., forest remnants to reduce potential response bias motivated by fear of sanctions related to the forest area that can be legally cleared in a landholding. The action, i.e., conserving or converting to agriculture; the context, i.e., the landholding; and the time, i.e., for the next year, were specific and consistent across surveys. Although these measures of intention do not assess preferences for combinations of outcomes explicitly, they reflect the inherent trade-offs present in any intention, and decision, of allocating a finite amount of resources, e.g., forest area, to alternative uses, e.g., forest conservation vs. pasture/crop cultivation.

We administered structured questionnaires to 89 landholders in 2012 to elicit self-reported measures of forest conservation and forest conversion intentions. Landholders were asked to rate the following statements using a bidirectional 5-point Likert scale (very strong [+2]/very weak [-2]): "My intention to maintain forest remnants undisturbed in my landholding for the next year is (very strong/very weak)" and "My intention to convert forest remnants to pasture or cropland in my landholding for the next year is (very strong/very weak)." The questionnaire also asked landholders about perceived barriers to materialize their land-use intentions, e.g., land tenure, access to capital. We plotted the self-reported measures of intention for each surveyed landholder to assess their willingness to trade-off between competing outcomes. Expectedly, the willingness to trade-off conservation and 
productivity of landholders of the same landholder type were clustered in the trade-off space. We chose best-fitting curves for each landholder type to portray the combinations of conservation and production outcomes for which they achieve the same level of satisfaction. Indifference curves therefore show that landholders of the same type will generally be indifferent to the combination of outcomes depicted by the curve.

\section{RESULTS}

\section{Identification of landholder types}

We classified landholders into one of three stakeholder groups characterized by an underlying agricultural regime. The first cluster $(n=15)$ was associated with a preproductivist agricultural regime because landholders identified themselves as stewards of the land (Wilson 2007). This identity built up during a long time of residence in these landscapes and of strong feedback interactions between local social and ecological systems. Preproductivist landholders of the Chaco developed a land-use system of low intensity and productivity known as puesto. Raising small livestock and cattle in puestos relied on the natural forage productivity of ecosystems and provided the subsistence base of households. The second cluster $(\mathrm{n}=5)$ was associated with a multifunctional agricultural regime because landholders showed a coexistence of production and conservation-oriented actions and thoughts (Wilson 2007). Multifunctional landholders were mostly from within the Chaco region and developed land-use systems combining elements of the native ecosystem and advances in modern agricultural technologies, for instance, silvopastoral systems integrating shade and forage trees and high-yielding pastures. The third cluster $(n=7)$ was associated with a productivist agricultural regime because they showed a strong attitude toward the intensification and expansion of an industrial mode of agriculture, to maximize production and economic output (Burton and Wilson 2006). Most productivist landholders arrived to the Chaco in the last two decades from the Pampas region, as also described by Manuel-Navarrete et al. (2009). They deployed land-use systems based on the total clearing of the native ecosystem for the cultivation of high-yielding pastures or crops on cleared areas. The strategy of productivist landholders was based on a tight connection with international markets of land and agricultural inputs and outputs. There was a close relationship between the psycho-social characteristics of landholder types and the level of land-use intensity of their landholdings, as indicated by the short distance between landholdings of the same typology in the trade-off space (Fig. 1).

\section{Biophysical efficiency of land-use systems}

We found a concave efficiency frontier showing a threshold response in avian diversity when agricultural productivity increased to above $60-70 \%$ of its agro-ecological potential (Fig. 1). It shows that as we increase land-use intensity on forests, avian diversity remains stable and even experiences a very slight increase until cattle productivity reaches $50-60 \%$ of its agro-ecological potential. In other words, $90-95 \%$ of the bird species found in nearby undisturbed forests can persist in land-use systems of low land-use intensity. However, avian diversity starts declining when we reach between $60-70 \%$ of achievable yields and drops sharply when land-use intensification pushes the system above $70 \%$ of its potential agricultural productivity. To illustrate this trend, an intermediate-intensity system provided habitat for $90 \%$ of bird species in nearby forests and achieved $60 \%$ of potential yields. Compared to this, a high-intensity system that achieved $20 \%$ higher productivity provided habitat for $50 \%$ fewer bird species.

Fig. 1. Efficiency frontier for combinations of avian diversity and agricultural productivity in Dry Chaco agricultural frontiers (modified from Mastrangelo and Gavin 2012).

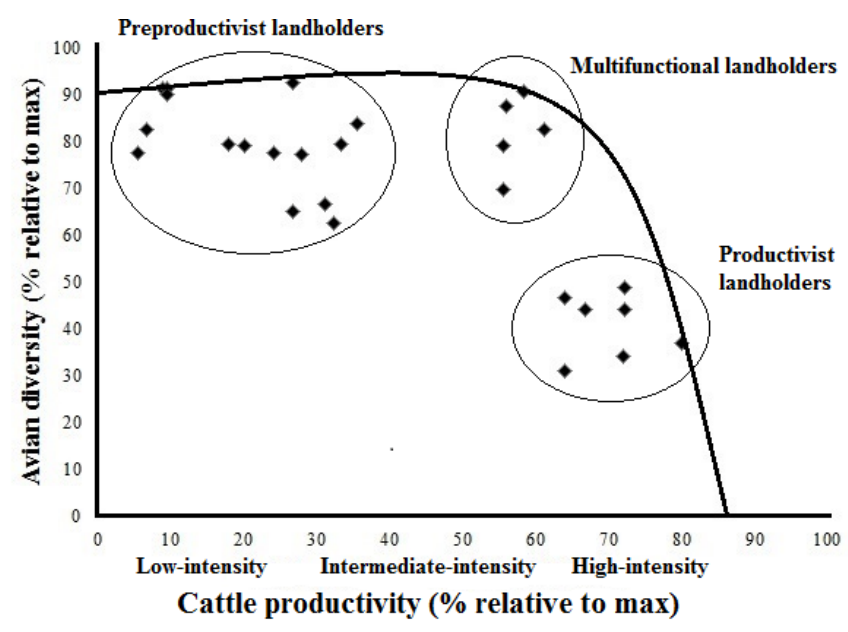

The proximity of a landholding to the efficiency frontier in the trade-off space indicates how efficient it is in balancing conservation and production objectives. Three out of five intermediate-intensity landholdings managed by multifunctional landholders were located at short distances from the efficiency frontier. The efficiency of low-intensity landholdings managed by preproductivist landholders ranged widely, with 4 out of 15 showing high efficiency, and 3 out of 15 being highly inefficient. High-intensity landholdings run by productivist landholders were the least efficient because three out of seven were located far from the efficiency frontier. Overall, the efficiency frontier shows that: (1) large gains in efficiency can be achieved by transitioning from low to intermediate-intensity systems because agricultural productivity can be increased by $35-65 \%$ without compromising avian diversity, (2) small gains in productivity in the transition from intermediate- to high-intensity systems bring large decreases in efficiency because it provokes large declines in avian diversity $(20-60 \%)$.

\section{Biophysical efficiency of policy options}

The projection of alternative land-use scenarios allowed assessing the relative utility of policy options to balance conservation and production outcomes (Table 2). Cattle productivity differed significantly among scenarios $(\mathrm{F}=72.87, \mathrm{p}<0.05)$. Cattle productivity under the industrial agriculture scenario was the highest, whereas that achieved under land sparing was not statistically different when compared to the land-sharing scenarios, with and without $30 \%$ of forests set aside. Moreover, cattle yields under the land-sparing scenario were $16.9 \%$ lower than under the land-sharing scenario. This result contradicts the widely held notion that integrating production and conservation on the same land, i.e., land-sharing, produces lower yields than combining land-use intensification and land set asides, i.e., land 
sparing (Phalan et al. 2011). Under the industrial agriculture scenario, the maximization of production outcomes via highintensity systems created a landscape devoid of native vegetation and only inhabited by less than one third of the bird species found in forests, all except one being habitat generalist species. The landsharing scenarios harbored more than twice the proportion of habitat generalist species found in matrix habitats compared to the industrial agriculture and land-sparing scenarios $(\mathrm{H}=33.46$, $\mathrm{p}<0.05$ ). The land-sharing scenario provided only $13.1 \%$ less yields than the industrial agriculture scenario, although it created a matrix that was used by one-quarter of the bird species restricted to forest habitats and two-thirds of the habitat generalist species native to the Chaco region. The proportion of forest specialist species found in matrix habitats under the land-sharing scenarios was statistically higher than that under the industrial agriculture and land-sparing scenarios $(\mathrm{H}=33.65, \mathrm{p}<0.05)$.

Under the land-sparing scenario, setting aside a forest area not lower than $30 \%$ of the landscape provided core habitat for all bird species detected, although high land-use intensities in the $70 \%$ of the landscape created a matrix with very low avian conservation value. The traditional ranching scenario allowed for the conservation of a large proportion of the forest specialist $(62.6 \%)$ and habitat generalist species $(84.8 \%)$ found in undisturbed forests. Compared to scenarios with $30 \%$ forest set asides, the proportion of habitat generalist species found under traditional ranching did not differ significantly, but the proportion of forest specialist species was statistically lower $(\mathrm{H}=21.75, \mathrm{p}<0.05)$. Larger populations of bird species may be supported under the traditional ranching compared to the land-sparing scenario because the extent of core habitat in the former was 3.3 times larger than in the latter. However, a landscape dominated by traditional ranching systems provided 8.7 and 7 times lower cattle yields than the land-sharing and land-sparing scenarios, respectively. Finally, the scenario combining land sharing and conservation set asides on the same landscape simultaneously provided: (1) core habitat for all Chaco avifauna in the $30 \%$ of undisturbed forest area, and (2) a high-quality matrix in the $70 \%$ of area covered by silvopastoral systems, which allowed the conservation of $23.8 \%$ and $36.5 \%$ more forest specialist and habitat generalist species in the matrix compared to the landsparing scenario, respectively. These larger conservation outcomes came at the cost of achieving only $9 \%$ less yields than under the land-sparing scenario.

\section{Social desirability of land-use systems}

Preproductivist landholders reported a very strong intention to conserve forests in their landholdings (Likert score $=1.52 \pm 0.67$ ) and a variable intention to convert these to agriculture (Likert score $=0.74 \pm 1.04)$. The indifference curve of preproductivist landholders (Fig. 2) shows a consistent intention to conserve forests in puestos, even when many of them also hold a strong intention to convert forest to agriculture. Intentions to convert forests in this group were oriented toward the clearing of small plots (1-10 hectares) for pasture cultivation. Multifunctional landholders reported a strong intention both to conserve and convert forests to agriculture (Likert scores $=1.12 \pm 0.89$ and 1.08 \pm 0.77 , respectively). Multifunctional landholders more willing to conserve forests had a relatively weaker intention to convert these for agriculture, and vice versa (Fig. 2). Finally, productivist landholders reported a strong to very strong intention to convert forests to agriculture (Likert score $=1.35 \pm 0.81)$ and a weak intention to conserve forest remnants (Likert score $=-0.76 \pm 0.89$ ). Productivist landholders more willing to convert forests to agriculture showed higher opposition toward setting aside some forest remnants (Fig. 2), suggesting that they would continue expanding cropland and pastures as long as they could access forestland and clear it.

Fig. 2. Indifference curves of preproductivist (- - ), multifunctional (----), and productivist (-.-.-) landholder groups, built upon combinations of intentions to conserve and convert forest remnants in their landholdings (indicated by black squares for preproductivist, dark grey diamonds for multifunctional, and light grey triangles for productivist landholders).

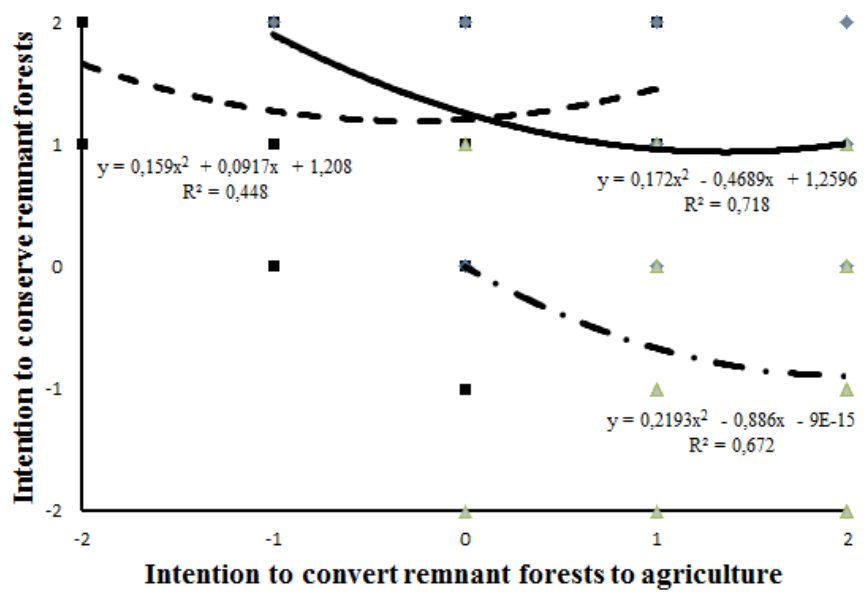

\section{DISCUSSION}

The combination of trade-off analysis and scenario simulation proved useful to describe and compare the biophysical potential of different landholding and landscape types to simultaneously provide ecosystem services. In addition, the joint assessment of the efficiency frontier and indifference curves allowed the identification of system states that provide high conservation and high production outcomes and fit within the preferences of landholders. Incorporating information about landholders' preferences into land-use policy design may increase the social acceptability and legitimacy of interventions, and thus, their effectiveness at halting deforestation in the Argentine Dry Chaco.

Trade-offs analyses are a logical starting point for identifying system states in which competing land-use objectives are efficiently and cost-effectively met (De Fries et al. 2004). In our case study, the implementation of intermediate-intensity silvopastoral systems by multifunctional landholders provided 'big gains' for conservation (30-50\% more birds) with 'small losses' for production (10-15\% less yields), compared to highintensity systems. The cost-effectiveness of integrating native trees and shrubs with high-yielding grasses was supported by the efficiency frontier and the scenario simulation. A silvopastoral matrix interspersed with forest fragments, i.e., land-sharing + conservation scenario, supported similar cattle productivity and 
a significantly higher proportion of forest habitat specialist and habitat generalist species than the land-sparing scenario.

For landscapes to deliver these joint benefits, the biophysical potential of land-use options must concur with the willingness of landholders to implement them. Thus, assessing indifference curves is a logical extension of trade-off analyses. Indifference curves showed balanced preferences for conservation and production outcomes in multifunctional landholders and a clear inclination of productivist landholders toward clearing forest for increasing productivity. Therefore, realizing the potential of landsharing scenarios in Chaco agricultural frontiers would require transitions from productivist to multifunctional agricultural regimes (Fig. 3, upward arrow).

Fig. 3. Social-ecological trade-offs and desired transitions between agricultural regimes in Dry Chaco agricultural frontiers. Multifunctional agricultural regimes simultaneously provide high conservation and high production outcomes. A transition from preproductivist to multifunctional regimes is motivated endogenously because of the willingness of preproductivist landholders to intensify some portions of their landholdings. In contrast, a transition from productivist to multifunctional regimes should be promoted exogenously through incentives and regulations as productivist landholders are not willing to conserve forests.

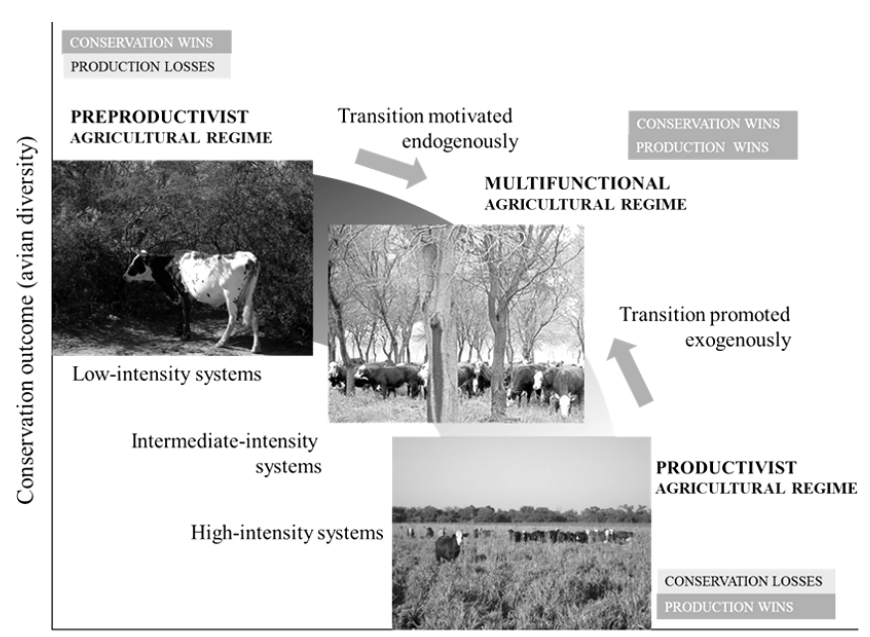

Production outcome (cattle yields)

In Chaco agricultural frontiers, low-intensity systems showing a high efficiency to balance conservation and production outcomes were managed by preproductivist landholders with a general preference toward conserving forest. Interestingly, this conservationist attitude coexisted in preproductivist landholders with a preference toward clearing small plots for crop and pasture cultivation. Therefore, it is expected that preproductivist landholders will maintain their low-intensity systems but that some portions of these may be intensified to increase cattle productivity, indicating a likely transition from preproductivists to more multifunctional agricultural regimes (Fig. 3, leftward arrow). Transitioning toward a land-sharing scenario via the convergence of preproductivist and productivist regimes into multifunctional ones will require well-informed policy design.
Knowing which transitions between agricultural regimes may increase efficiency, and to what extent landholders are willing to undergo such transitions, is important for the design of policy interventions. Preproductivist landholders are willing to selectively clear the woody understory in small portions of their landholdings to favor grass species of higher and more stable productivity and to allow cattle to graze under the shade. Thus, it is the landholders themselves who promote the efficiency gain associated with moving from preproductivist to multifunctional regimes, i.e., endogenously motivated transition (Fig. 3). Unfortunately, insecure land tenure among most preproductivist landholders precludes them from accessing and investing capital to develop silvopastoral systems.

In contrast, productivist landholders are not generally willing to set aside forest fragments or plant native trees and shrubs in cleared areas, although evidence exists that these practices would increase the long-term stability and productivity of their systems (Murgueitio et al. 2011). In the absence of endogenous motivations, increasing conservation outcomes in productivist regimes requires exogenous interventions tailored to the behavior of productivist landholders, i.e., exogenously promoted transition (Fig. 3). Interventions such as land-use zoning and payments for ecosystem services are incipient in the Argentine Dry Chaco. However, the effectiveness of these incentives and regulations has been low in part because of insufficient consideration of landholders' behavior (Seghezzo et al. 2011).

Our research is a first step in the integration of stakeholders' preferences into analysis of ecosystem services supply in the Argentine Dry Chaco. Further work is needed for a more precise assessment of landholder preferences, and thus to reduce potential gaps between declared intentions and observed behavior. Psycho-social factors such as the opinions and perceived expectations of peer landholders were found to strongly modulate smallholders' intentions to conserve forest fragments (Mastrangelo et al. 2014a). Research into the dynamics of landholder groups may help understand and design interventions to influence individual preferences. In addition, mapping interactions between landholder groups and with stakeholders at larger scales, i.e., national government and international markets, would be required to fully capture the complexity of socialecological trade-offs in agricultural frontiers.

Finally, institutional factors play a crucial role in the likelihood of land-use transitions, whether acting as barrier, e.g., land-tenure insecurity, or enabling factors, e.g., policy incentives and regulations. Conservation and development outcomes in the agricultural frontier may be as much related to distribution and access to land, as to agricultural productivity. Thus, answering how land-use transitions may fit into existing institutional arrangements or be promoted via available mechanisms should complement the analysis of its biophysical efficiency and social desirability. A stronger focus on the social and institutional factors influencing access to ecosystem services in the Argentine Dry Chaco will be needed to better inform policy design.

Responses to this article can be read online at: http://www.ecologyandsociety.org/issues/responses. $\mathrm{php} / 7186$ 


\section{Acknowledgments:}

We thank two anonymous reviewers for their helpful comments on a previous version of the manuscript. This work was carried out with the aid of grants from the Inter-American Institute for Global Change Research (IAI) CRN3095, which is supported by the U.S. National Science Foundation (Grant GEO-1128040), the IberoAmerican Programme for Science, Technology and Development (VESPLAN Thematic Network 413RT0472), the Research Fund for Science and Technology of Argentina (FONCYT, PICT08-0020 and PICT012-0607), the National Institute of Agricultural Research and Technology of Argentina (INTA), and the National University of Mar del Plata.

\section{LITERATURE CITED}

Berti, R. 2009. Sustentabilidad de los sistemas ganaderos. Technical report. National Institute of Agricultural Technology, Salta, Argentina.

Burton, R. J. F., and G. A. Wilson. 2006. Injecting social psychology theory into conceptualizations of agricultural agency: towards a post-productivist farmer self-identity? Journal of Rural Studies 22:95-115. http://dx.doi.org/10.1016/j.jrurstud.2005.07.004

Cavender-Bares, J., S. Polasky, E. King, and P. Balvanera. 2015. A sustainability framework for assessing trade-offs in ecosystem services. Ecology and Society 20(1): 17. http://dx.doi.org/10.5751/ ES-06917-200117

DeFries, R. S., J. A. Foley, and G. P. Asner. 2004. Land-use choices: balancing human needs and ecosystem function. Frontiers in Ecology and the Environment 2(5):249-257. http://dx. doi.org/10.1890/1540-9295(2004)002[0249:LCBHNA]2.0.CO;2

Di Rienzo, J. A., F. Casanoves, M. G. Balzarini, L. Gonzalez, M. Tablada, and C. W. Robledo. 2008. InfoStat. Version 2008. Grupo InfoStat, FCA, Universidad Nacional de Córdoba, Córdoba, Argentina.

Eva, H. D., A. S. Belward, E. E. De Miranda, C. M. Di Bella, V. Gond, O. Huber, S. Jones, M. Sgrenzaroli, and S. Fritz. 2004. A land cover map of South America. Global Change Biology 10 (5):731-744. http://dx.doi.org/10.1111/j.1529-8817.2003.00774.x

Grau, H. R., N. I. Gasparri, and T. M. Aide. 2008. Balancing food production and nature conservation in the Neotropical dry forests of northern Argentina. Global Change Biology 14(5):985-997. http://dx.doi.org/10.1111/j.1365-2486.2008.01554.X

Grau, R., T. Kuemmerle, and L. Macchi. 2013. Beyond 'land sparing versus land sharing': environmental heterogeneity, globalization and the balance between agricultural production and nature conservation. Current Opinion in Environmental Sustainability 5(5):477-483. http://dx.doi.org/10.1016/j.cosust.2013.06.001

Hein, L., K. van Koppen, R. S. de Groot, and E. C. van Ierland. 2006. Spatial scales, stakeholders and the valuation of ecosystem services. Ecological Economics 57:209-228. http://dx.doi. org/10.1016/j.ecolecon.2005.04.005

Hoekstra, J. M., T. M. Boucher, T. H. Ricketts, and C. Roberts. 2005. Confronting a biome crisis: global disparities of habitat loss and protection. Ecology Letters 8(1):23-29. http://dx.doi. org/10.1111/j.1461-0248.2004.00686.x
Macchi, L., H. R. Grau, P. V. Zelaya, and S. Marinaro. 2013. Trade-offs between land use intensity and avian biodiversity in the Dry Chaco of Argentina: a tale of two gradients. Agriculture, Ecosystems and Environment 174:11-20. http://dx.doi.org/10.1016/ j.agee.2013.04.011

Manuel-Navarrete, D., G. Gallopín, M. Blanco, M. Díaz-Zorita, D. O. Ferraro, H. Herzer, P. Laterra, M. R. Murmis, G. P. Podestá, J. Rabinovich, E. H. Satorre, F. Torres, and E. F. Viglizzo. 2009. Multi-causal and integrated assessment of sustainability: the case of agriculturization in the Argentine Pampas. Environment, Development and Sustainability 11(3):621-638. http://dx.doi. org/10.1007/s10668-007-9133-0

Mastrangelo, M. E., and M. C. Gavin. 2012. Trade-offs between cattle production and bird conservation in an agricultural frontier of the Gran Chaco of Argentina. Conservation Biology 6:1040-1051. http://dx.doi.org/10.1111/j.1523-1739.2012.01904. $\underline{x}$

Mastrangelo, M. E., and M. C. Gavin. 2014. Impacts of agricultural intensification on avian richness at multiple scales in Dry Chaco forests. Biological Conservation 179(0):63-71. http:// dx.doi.org/10.1016/j.biocon.2014.08.020

Mastrangelo, M. E., M. C. Gavin, P. Laterra, W. L. Linklater, and T. L. Milfont. 2014a. Psycho-social factors influencing forest conservation intentions on the agricultural frontier. Conservation Letters 7(2):103-110. http://dx.doi.org/10.1111/conl.12033

Mastrangelo, M. E., F. Weyland, S. H. Villarino, M. P. Barral, L. Nahuelhual, and P. Laterra. 2014b. Concepts and methods for landscape multifunctionality and a unifying framework based on ecosystem services. Landscape Ecology 29(2):345-358. http://dx. doi.org/10.1007/s10980-013-9959-9

Morello, J., W., Pengue, and A. F. Rodríguez. 2005. Etapas de uso de los recursos y desmantelamiento de la biota del Chaco. Fronteras 4:1-17.

Murgueitio, E., Z. Calle, F. Uribe, A. Calle, and B. Solorio. 2011. Native trees and shrubs for the productive rehabilitation of tropical cattle ranching lands. Forest Ecology and Management 261:1654-1663. http://dx.doi.org/10.1016/j.foreco.2010.09.027

Ostrom E. 2009. A general framework for analyzing sustainability of social-ecological systems. Science 325:419-422. http://dx.doi. org/10.1126/science.1172133

Phalan, B., A. Balmford, R. E. Green, and J. P. Scharlemann. 2011. Minimising the harm to biodiversity of producing more food globally. Food Policy 36:S62-S71. http://dx.doi.org/10.1016/ j.foodpol.2010.11.008

Schulze, C. H., M. Waltert, P. J. A. Kessler, R. Pitopang, D. Veddeler, M. Mühlenberg, S. R. Gradstein, C. Leuschner, I. Steffan-Dewenter, and T. Tscharntke. 2004. Biodiversity indicator groups of tropical land-use systems: comparing plants, birds, and insects. Ecological Applications 14(5):1321-1333. http://dx.doi. org/10.1890/02-5409

Seghezzo, L., J. N. Volante, J. M. Paruelo, D. J. Somma, E. C. Buliubasich, H. Rodríguez, S. Gagnon, and M. Hufty. 2011. Native forests and agriculture in Salta (Argentina): conflicting visions of development. Journal of Environment and Development 20(3):251-277. http://dx.doi.org/10.1177/1070496511416915 
Smith, F. P., R. Gorddard, A. P. N. House, S. McIntyre, and S. M. Prober. 2012. Biodiversity and agriculture: production frontiers as a framework for exploring trade-offs and evaluating policy. Environmental Science and Policy 23:85-94. http://dx.doi. org/10.1016/j.envsci.2012.07.013

Vallejos, M., J. N. Volante, M. J. Mosciaro, L. M. Vale, M. L. Bustamante, and J. M. Paruelo. 2014. Transformation dynamics of the natural cover in the Dry Chaco ecoregion: a plot level geodatabase from 1976 to 2012. Journal of Arid Environments. http:// dx.doi.org/10.1016/j.jaridenv.2014.11.009

Whelan, C. J., D. G Wenny, and R. J. Marquis, 2008. Ecosystem services provided by birds. Annals of the New York Academy of Sciences 1134(1):25-60. http://dx.doi.org/10.1196/annals.1439.003

Wilson, G. A. 2007. Multifunctional agriculture: a transition theory perspective. CABI, Wallingford, UK http://dx.doi. org/10.1079/9781845932565.0000 